\title{
ЭВОЛЮЦИЯ ПОНЯТИЯ КОНСТИТУЦИОННОГО ПРАВА ГРАЖДАН РОССИЙСКОЙ ФЕДЕРАЦИИ НА ДОСТОВЕРНУЮ ИНФОРМАЦИЮ О СОСТОЯНИИ ОКРУЖАЮЩЕЙ СРЕДЫ
}

Савченко М.С., Кубанский государственный аграрный университет им. И.Т. Трубилина, г. Краснодар, Российская Федерация, Milena.555@mail.ru

Грицай Д.В., Кубанский государственный аграрный университет им. И.Т. Трубилина, Краснодарский филиал Института проблем глобализации, г. Краснодар, Российская Федерация, niipgergo2009@mail.ru

Настоящая статья посвящена исследованию эволюции понятия конституционного права граждан Российской Федерации на достоверную информацию о состоянии окружающей среды. Актуальность данной проблемы, по мнению авторов статьи, обусловлена стремительно ухудшающимся экологическим состоянием окружающей среды, возрастающим негативным воздействием на нее антропогенного фактора, а также неспособностью органов власти в большинстве государств создать адекватный правовой механизм охраны и защиты окружающей среды, который позволил бы обеспечить ее устойчивое сохранение и развитие. В статье использовался ряд методов научного исследования, в частности: анализа; синтеза; классификации; сравнительно-правовой; исторический. Обосновывается авторский подход к проведению анализа этапов возникновения и закрепления права граждан Российской Федерации на достоверную информацию о состоянии окружающей среды в законодательстве страны путем опоры на хронологию его первичной институционализации, раскрытия и конкретизации в российских нормативных правовых актах. По мнению авторов, создание дополнительных условий для реализации права граждан на достоверную информацию о состоянии окружающей среды позволит улучшить экологическую обстановку в России и мире.

Ключевые слова: экологическое право, конституция, Российская Федерация, понятие, достоверная информация, окружающая среда, $\mathrm{OOH}$, народ, международный, защита.

DOI: $10.21779 / 2224-0241-2020-33-1-61-67$

UDC 342.571

\section{EVOLUTION OF THE CONCEPT OF THE CONSTITUTIONAL RIGHT OF CITIZENS OF THE RUSSIAN FEDERATION TO RELIABLE INFORMATION ABOUT THE STATE OF THE ENVIRONMENT}

Savchenko M.S., Kuban state agrarian university named after I. T. Trubilin, Krasnodar, Russian Federation, Milena.555@mail.ru

Gritsay D.V., Kuban state agrarian university named after I. T. Trubilin, Krasnodar branch of the Institute of globalization problems, Krasnodar, Russian Federation, niipgergo2009@mail.ru

This article is devoted to the study of the evolution of the concept of the constitutional right of citizens of the Russian Federation to reliable information about the state of the environment. The relevance of this problem, according to the authors, due to the rapidly deteriorating ecological environment, the increasing negative impact of human factor and the inability of authorities in most States to create an adequate legal mechanism of protection of the environment, which would ensure its sustainable preservation and development. The article used a number of methods of scientific research, in particular: analysis; synthesis; classification; comparative legal; historical. The article substantiates the author's approach in analyzing the stages of emergence and consolidation of the right of citizens of the Russian Federation to reliable information about the state of the environment in the legislation of the country, by relying on the chronology of its primary institutionalization, disclosure and concretization in Russian legal acts. According to the authors, the creation of additional conditions for the realization of the right of citizens to reliable information about the state of the environment will improve the environmental situation in Russia and the world.

Key word: environmental law; Constitution; Russian Federation; concept; reliable information; environment; UN; people; international; protection. 
Проблема получения достоверной информации о состоянии окружающей среды в наше время является одной из самых актуальных тем для обсуждения в научной и учебной литературе $[1$, c. $755 ; 2$, с. $124 ; 3$, с. 1358$]$. Кроме того, во всем мире решение данной проблемы является объектом пристального внимания со стороны законодателей.

Актуальность данной проблемы обусловлена стремительно ухудшающимся экологическим состоянием окружающей среды, возрастающим негативным воздействием на нее антропогенного фактора, а также неспособностью органов власти в большинстве государств создать адекватный правовой механизм охраны и защиты окружающей среды, который позволил бы обеспечить ее устойчивое сохранение и развитие.

Эти обстоятельства послужили своеобразным толчком к формированию новой отрасли российской правовой науки - «Экологическое право», а также соответствующей отрасли российского законодательства.

Осознание необходимости разрешения проблемы получения достоверной информации о состоянии окружающей природной среды повлияло и на авторов действующей Конституции Российской Федерации при закреплении в ней права граждан России на благоприятную окружающую среду и достоверную информацию о ее состоянии.

Исследовать структуру и содержание права граждан Российской Федерации на достоверную информацию о состоянии окружающей среды можно, опираясь не только на Основной закон страны, но и на иные нормативные правовые акты, регулирующие права, свободы и законные интересы граждан (в том числе в области экологии). Данное право состоит в гарантированной Основным законом страны и действующим законодательством возможности получения гражданами России неискаженной информации, касающейся состояния окружающей среды и мерами по ее охране (далее экологическая информация).

При этом приоритетное значение имеет важная информация, отражающая процессы и явления, происходящие в сфере взаимодействия природы и общества, а также необходимые методы и способы защиты окружающей среды. Так, по мнению М.М. Бринчука, «экологическая информация содержит в себе следующие данные: состояние земли, почвы, недр, воды, атмосферного воздуха, фауны, флоры, природных комплексов; об экологической угрозе или риске для здоровья и жизни людей; о химических, физических и биологических воздействиях на состояние окружающей среды и их источниках; о деятельности, отрицательно влияющей или могущей повлиять на природные объекты; о мерах по охране окружающей среды, в том числе правовых, административных и иных мерах» [4, с. 211$]$.

В связи с этим можно сделать вывод о том, что информированность граждан Российской Фе- дерации о состоянии окружающей среды является необходимым условием обеспечения охраны их жизни и здоровья. Отсутствие же подобной информации, с одной стороны, способствует росту числа заболеваний среди населения, а с другой - способно стать катализатором роста социальной напряжённости в обществе (примеры тому имелись в последние годы существования СССР, когда отсутствие объективной информации о состоянии окружающей среды воспринималось населением как умышленное сокрытие якобы имевших место экологических катастроф) [5, с. 11].

В данной статье мы исследуем этапы возникновения и закрепления права граждан Российской Федерации на достоверную информацию о состоянии окружающей среды в законодательстве страны, опираясь на хронологию его первичной институционализации, раскрытия и конкретизации в нормативных правовых актах.

Этот метод качественно отличается от попыток исследования эволюции данного права иными авторами, закрепляющими в качестве основания ее типологизации лишь место закрепления права граждан Российской Федерации на достоверную информацию о состоянии окружающей среды (конкретные виды нормативных правовых актов) [4; 6]. Он позволит не только исследовать эволюцию развития данного права, но и проанализировать этапы изменения отношения власти к праву на экологическую информацию.

Рассмотрим понятие «право граждан Российской Федерации на достоверную информацию о состоянии окружающей среды» через призму более общего понятия «право на информацию». Данное право впервые было закреплено в Законе РСФСР от 27.12.1991 г. № 2124-1 «О средствах массовой информации», согласно статье 38 которого «граждане имеют право на получение через СМИ достоверных сведений о деятельности государственных органов, органов местного самоуправления, организаций, общественных объединений, их должностных лиц». Закрепление права граждан страны на информацию выступило одним из первых шагов Российской Федерации на пути к расширению возможностей населения на получение точных неискаженных полных сведений о ситуации в государстве.

Однако формирование данного права в 1991 году только начиналось. В 1993 году принимается Конституция России, в которой в части 2 статьи 24 была закреплена обязанность обеспечения государственными органами каждому гражданину возможности ознакомления с документами и материалами, непосредственно затрагивающими его права и свободы. Данная статья тесно перекликается с частью 4 статьи 29, указывающей, что каждый может свободно искать, получать, передавать, производить и распространять информацию любым законным способом (правда, в ней есть ого- 
ворка, ограничивающая оборот информации, являющейся государственной тайной).

Анализ части 2 статьи 5 Закона Российской Федерации «О государственной тайне» от 21.07.1993 г. № 5485-1 позволяет сделать вывод о том, что информация о состоянии окружающей среды не является государственной тайной и, следовательно, ее могут получать, передавать, производить и распространять граждане России и юридические лица любыми законными способами.

Однако действительность такова, что граждане нашей страны зачастую не знают, что у них есть право не только на благоприятную окружающую среду и достоверную информацию о ее состоянии, но и на возмещение ущерба, причиненного их здоровью или имуществу экологическим правонарушением. Это обстоятельство, по нашему мнению, обусловлено плохими знаниями гражданами Российской Федерации Основного закона страны, что подтверждается и опросами социологов. Так, согласно опросу ВЦИОМ в 2018 году, Индекс информированности о содержании Конституции Российской Федерации не превышает $6 \%$ [7].

Также хочется обратить внимание на вышедший в 1993 году Указ Президента Российской Федерации «О дополнительных гарантиях прав граждан на информацию», согласно которому для граждан стали доступны: «информация, выражающая общественный интерес или затрагивающая их личные интересы; обязательное систематическое информирование граждан о предполагаемых или принятых решениях; создание условий для обеспечения граждан Российской Федерации зарубежными информационными продуктами и оказания им информационных услуг, имеющих зарубежное происхождение». Таким образом, в который раз законодательная ветвь власти конкретизировала право граждан на информацию, от которого напрямую зависит гражданское право на достоверную информацию о состоянии окружающей среды.

Важное значение в динамике развития процесса раскрытия и конкретизации содержания права граждан Российской Федерации на достоверную информацию о состоянии окружающей среды в действующем законодательстве сыграли: Закон Российской Федерации от 10.06.1993 г. № 5154-1 «О стандартизации», закрепивший принципы формирования российских стандартов качества товаров, работ и услуг; Федеральный закон от 21.12.1994 г. № 68-Ф3 «О защите населения и территорий от чрезвычайных ситуаций природного и техногенного характера», который предусмотрел обязанность органов государственной власти субъектов Российской Федерации информировать население о чрезвычайных ситуациях; Федеральный закон от 23.11.1995 г. №174-Ф3 «Об экологической экспертизе», закрепивший в 19 статье право граждан и общественных организаций (объединений) получать информацию от специально уполномо- ченных государственных органов, отвечающих за проведение государственной экологической экспертизы конкретных объектов; Федеральный закон от 09.01.1996 г. № 3-Ф3 «О радиационной безопасности населения», предоставивший право гражданам и юридическим лицам на получение объективной информации от организации, осуществляющей деятельность с использованием источников ионизирующего излучения, в пределах выполняемых ею функций о радиационной обстановке и принимаемых мерах по обеспечению радиационной безопасности; Федеральный закон от 04.07.1996 г. № 85-Ф3 «Об участии в международном информационном обмене», предоставивший возможность гражданам получать международную и зарубежную информацию о состоянии окружающей природной среды; Федеральный закон от 19.07.1998 г. № 113-Ф3 «О гидрометеорологической службе», закрепивший право граждан на получение информации об изменениях состояния природной среды.

Отдельно хочется отметить роль в этом процессе Кодекса Российской Федерации об административных правонарушениях от 30.12.2001 г. № 195-Ф3, закрепившего возможность привлечения виновных лиц к ответственности за: «сокрытие, умышленное искажение или несвоевременное сообщение полной и достоверной информации: о состоянии окружающей среды и природных ресурсов; об источниках загрязнения окружающей среды и природных ресурсов или иного вредного воздействия на окружающую среду и природные ресурсы; о радиационной обстановке; о данных, полученных при осуществлении производственного экологического контроля; об информации, содержащейся в заявлении о постановке на государственный учет объектов, оказывающих негативное воздействие на окружающую среду» [16].

Последним в хронологическом порядке является Федеральный закон от 10.01.2002 г. № 7-Ф3 «Об охране окружающей среды», закрепивший «право каждого гражданина на получение достоверной информации о состоянии окружающей среды (а что еще интереснее - участие граждан в принятии решений, касающихся их прав на благоприятную окружающую среду); право граждан направлять обращения в соответствующие органы и должностным лицам о получении своевременной, полной и достоверной информации о состоянии окружающей среды в местах своего проживания и мерах по ее охране; обязанность формирования и ведения единой информационной базы данных в области охраны окружающей среды» [17].

Напрашивается вывод о том, что в нашем законодательстве право граждан на достоверную информацию об окружающей среде представлено достаточно широко и детализировано во многих документах. Это наталкивает на мысль о том, что власти осознают всю важность экологического вопроса. Проследив в хронологическом порядке изменения и дополнения, мы увидели закономер- 
ность развития государства и его нормативных правовых актов.

Можно задаться вопросом относительно того, было ли закреплено право граждан на достоверную информацию об окружающей среде в законодательстве СССР? Анализ советского законодательства показывает, что ни в одной из Конституций СССР и РСФСР не было закреплено право граждан на достоверную информацию о состоянии окружающей среды.

В этой связи М.М. Бринчук пишет о том, что «катастрофа в Чернобыле послужила своеобразным катализатором возникновения потребности в обществе на получение информации о состоянии окружающей природной среды» [4, с. 311], то есть, сами законодатели в СССР не задумывались над данным правом граждан. Регулирование этого вопроса являлось следствием ужасной трагедии мирового масштаба. На наш взгляд, именно это стало хорошим примером для составителей Конституции Российской Федерации, ведь они, поняв насколько необходимо право на экологическую информацию для успешной жизнедеятельности человека и гражданина, внесли соответствующее право в новый Основной закон нашей страны.

Но как же в остальных странах закреплено право граждан на достоверную информацию об окружающей среде?

Прежде чем перейти к изучению закрепления данного права в некоторых зарубежных странах, будет нелишним упомянуть о международных документах, которые обеспечивают данное право. Многие из них ратифицированы в большинстве стран мира и носят обязательный к применению порядок.

Явными примерами могут служить:

1) Декларация Конференции Организации Объединенных Наций по проблемам окружающей человека среды 1972 года, принятая Конференцией Организации Объединенных Наций по проблемам окружающей человека среды в Стокгольме. В своем девятнадцатом принципе она закрепила положение о том, что «важно также, чтобы средства общественной информации не способствовали ухудшению окружающей среды, а, напротив, распространяли знания, касающиеся необходимости охраны и улучшения окружающей среды, с целью обеспечения возможностей всестороннего развития человека» [8].

2) Рио-де-Жанейрская декларация по окружающей среде и развитию, принятая Конференцией ООН по окружающей среде и развитию в 1992 году, которая являлась продолжением Декларации Конференции Организации Объединенных Наций по проблемам окружающей человека среды 1972 года. Она провозглашала, что «государство должно предоставлять гражданам экологическую информацию для осведомленности и участия населения в решении ухудшения состояния окружающей среды (принцип 10)» [9].
3) Конвенция «О доступе к информации, участии общественности в процессе принятия решений и доступе к правосудию по вопросам, касающимся окружающей среды» от 25.06.1998, принятая в Орхусе. Она определяет: «доступ к экологической информации; сбор и распространение экологической информации; участие общественности в решении вопросов, касающихся планов, программ и политики, связанных с окружающей средой; закрепляет подвид экологической информации - информацию о состоянии здоровья и безопасности людей» [10]. Однако следует отметить, что Орхусская Конвенция не была ратифицирована Россией, хотя и не противоречит статьей 42 Конституции Российской Федерации.

Как же обстоит дело с правом граждан на достоверную информацию о состоянии окружающей среды в отдельно взятых странах (на примере Республики Беларусь, ФРГ и США)?

Так, анализ белорусского законодательства показал, что в Республике Беларусь (как и в России) данное право закреплено в Конституции. В частности, в статье 34 закрепляется и гарантируется право граждан на получение достоверной своевременной информации о состоянии окружающей среды [11]. Однако в этой же статье есть оговорка о том, что «пользование информацией может быть ограничено законодательством в целях защиты чести, достоинства, личной и семейной жизни граждан и полного осуществления ими своих прав».

Также стоит отметить, что Республика Беларусь ратифицировала вышеупомянутую Орхусскую конвенцию в 1999 году. В целом система экологического законодательства в Республике Беларусь во многом схожа с российской, что легко объясняется тем, что оба государства наследники CCCP.

В свою очередь, ФРГ располагает большим количеством нормативных правовых актов, посвященных правам граждан на достоверную информацию об окружающей среде. Жители страны имеют право на получение экологической информации согласно «Закону об экологической информации», принятому 08.07.1994 г. [12]. Но, несмотря на это, в Основном законе ФРГ данное право не закреплено.

Уровень заинтересованности граждан в стране настолько велик, что в Германии даже имеется партия «Зеленых», которая занимается освещением экологических проблем. То есть даже отсутствие закрепления экологических прав в Конституции не мешает немцам чувствовать себя притесненными этим обстоятельством, так как они уверены, что их государство все равно обеспечит им информацию о состоянии природы, благодаря наличию в парламенте заинтересованной в этом партии. Если сравнивать с нашей страной, то уровень осознанности граждан здесь гораздо выше, они сами стремятся к защите этого права, хотя в России оно имеет большую юридическую значимость, чем у них. 
Соединенные Штаты Америки, одна из самых влиятельных стран мира, не отстает от других стран в предоставлении гражданам данного права. В стране существует Закон о свободе информации 1966 года [13], по которому граждане имеет право не только на достоверную информацию о состоянии окружающей среды, но также на принятие административных решений по данному вопросу, участие в открытых судебных заседаниях, касающихся экологической безопасности.

Источниками информации для жителей США являются ведомства, которые по требованию обязаны предоставить абсолютно бесплатно любую информацию, касающуюся данной темы, а также предприятия, регулярно готовящие отчеты о воздействии на окружающую среду. Однако в США, в отличие от России, не может быть проведена общественная экологическая экспертиза, а само право на достоверную информацию, закрепленное в Декларации, не конкретизировано.

В заключение можно сделать ряд выводов:

1. Эволюция права на экологическую информацию началась в XX веке и продолжается до сих, так как появляются все новые и новые документы, в которых данное понятие расширяется, что позволяет гражданам получать больше сведений не только о состоянии окружающей среды, но также о мерах по ее защите. При этом право человека и гражданина на получение информации об окружающей среде закреплено как на международном уровне (в нормативно-правовых актах международных правительственных и неправительственных организаций), так и на уровне отдельных государств. При этом развитие международного и национального экологического законодательства осуществляется поступательно. После крупных экологических катастроф, например, Чернобыльской трагедии, аварии на АЭС в Фукусиме и т.п., общественное мнение оказывает серьезное давление на национальные правительства и международные организации в части ускорения вопросов модернизации экологического, природоохранного законодательства. Однако подобную практику нельзя назвать позитивной. Но замедление темпов мирового экономического развития, стагнация экономик ряда стран, препятствует развитию экологического законодательства, так как охрана окружающей среды и внедрение профилактических и восстановительных технологий, проведение мероприятий по модернизации соответствующего оборудования требуют колоссальных финансовых вложений.

2. В настоящее время не все страны закрепили в своих основных законах право граждан на достоверную информацию о состоянии окружающей среды, однако надо не отметить, что большинство государств понимает важность этого. Многие страны, игнорирующие необходимость закрепления в национальном законодательстве системы природоохранных норм, включая право граждан на достоверную информацию о состоянии окружающей среды, относится к категории развивающихся государств. Данные страны, с одной стороны, не имеют финансовой возможности для разработки и внедрения технологий по охране окружающей среды, a, с другой стороны, их экономики во многом конкурентоспособны на мировом рынке в силу игнорирования норм международного экологического, природоохранного законодательства. В связи с этим требуются разработка и закрепление на международном уровне систем мероприятий по стимулированию развития экологического, природоохранного законодательства в развивающихся странах. Подобными мерами, с одной стороны, могут выступать экологические программы, финансируемые экономически развитыми государствами, а с другой - внедрение жестких дискриминационных мер в международной торговле в отношении стран, в которых игнорируется необходимость соблюдения международного экологического, природоохранного законодательства и закрепления в национальных правовых системах соответствующих правовых норм и институтов.

3. Имеет место динамика ухудшения экологической обстановки в России и мире. Так, Российская Федерация по уровню экологии в 2018 году занимала 52 место [14], а по уровню смертности от экологических проблем в 2016 году - 115 место [15]. Наша страна могла бы достичь лучших результатов, если бы граждане России более активно пользовались своим правом на достоверную информацию о состоянии окружающей среды. В связи с этим в Российской Федерации следует разработать и внедрить систему мероприятий по развитию правовой экологической культуры среди населения. В частности, в действующем законодательстве следует закрепить возможность обнародования данных о состоянии окружающей среды как на федеральном, так и на региональном и муниципальном уровнях. Как вариант, можно ввести в систему органов власти России институт уполномоченного по охране окружающей среды в Российской Федерации, приняв соответствующий федеральный закон. Уполномоченного по охране окружающей среды в Российской Федерации следует наделить полномочиями по осуществлению проверок соблюдения действующего экологического и природоохранного законодательства любыми юридическими лицами, особенно осуществляющими производственную деятельность (с возможностью, с одной стороны, обращаться в суд и иные правоохранительные органы в части пресечения нарушения действующего законодательства, а с другой приостановления деятельности юридических лиц, если она наносит вред окружающей среде). Это позволит привлечь внимание общества к проблемам окружающей среды в России, а также наладить полноценный постоянный диалог власти и гражданского общества по данной проблематике. 
4. В свою очередь, природоохранное и экологическое законодательство нуждается в дальнейшем совершенствовании и развитии, в том числе путем активного использования норм международного права. При этом, с одной стороны, отдельные позитивнее разработки национальных правовых систем в области экологического и природоохранного законодательства должны институционализироваться на международном уровне. А с другой стороны, на международном уровне следует разработать и принять типовые модельные кодексы (законы) для их последующего использования в разработке национального законодательства, особенно в развивающихся государствах. Это позволит в масштабах всей планеты унифицировать нормативно-правовую базу в области охраны окружающей среды.

\section{Литература}

1. Фролова Н.А. Некоторые проблемы реализации конституционного права на достоверную информацию о состоянии окружающей среды // Аллея науки. 2019. Т. 2. № 1 (28). С. 755-759.

2. Мельникова В.Г. Открытие данные в механизме реализации права граждан на достоверную информацию о состоянии окружающей среды // Вестник Томского государственного университета. Сер.: Право. 2017. № 23. С. 124-130.

3. Гусейнова Р.А. Право граждан на информацию о состоянии окружающей среды // Актуальные вопросы современной экономики. 2019. № 4. С. 1358-1367.

4. Бринчук М.М. Экологическое право: учебник. М., 2011. 624 с.

5. Жилин С.М. Экология. Информация. Общество: монография. Калининград, 2000. 310 с.

6. Экологическое право: учебник / под ред. О.И. Крассова. 4-е изд., пересмотр. М.: Юр. норма, НИЦ ИНФРА-М, 2019. 528 с.

7. ВЦИОМ. Индекс информированности о содержании Конституции за 2018 год. [Электронный pecypc]. URL: https://wciom.ru (дата обращения: 25.12.2019).

8. Декларация Конференции Организации Объединенных Наций по проблемам окружающей человека среды 1972 года // Международное экологическое законодательство: сб.ст. Киев, 2019. 414 с.

9. Рио-де-Жанейрская декларация Организации Объединенных Наций по окружающей среде и развитию 1992 года // Международное экологическое законодательство: сб. ст. Киев, 2019. 414 с.

10. О доступе к информации, участии общественности в процессе принятия решений и доступе к правосудию по вопросам, касающимся окружающей среды: конвенция Европейской Экономической Комиссии Организации Объединенных Наций от 25 июня 1998 г. // Международное экологическое законодательство: сб. ст. Киев, 2019. 414 с.

11. Конституция Республики Беларусь от 15 марта 1994 г. Минск, 2019. 37 с.

12. Об экологической информации: закон ФРГ от 8 июля 1994 г. // Зарубежное экологическое законодательство: сб. Калининград, 1996. 309 с.

13. Закон о свободе информации 1966 года США // Зарубежное экологическое законодательство: сб. Калининград, 1996. 309 с.

14. The Environmental Performance Index 2018 год. [Электронный pecypc]. URL: https://epi.envirocenter.yale.edu/downloads/epi2018policymakerssummaryv01.pdf (дата обращения: 25.12.2019).

15. Всемирная организация здравоохранения: официальный сайт. [Электронный ресурc]. URL: https://www.who.int/ru (дата обращения: 25.12.2019).

16. Кодекс Российской Федерации об административных правонарушениях от 30 дек. 2001 г. № 195-Ф3. М., 2019. 63 c.

17. Об охране окружающей среды: федер. закон Рос. Федерации от 10 янв. 2002 г. № 7-ФЗ: с изм. и доп. Доступ из справ.-правовой системы «КонсультантПлюс».

\section{References}

1. Frolova N.A. Nekotorye problemy realizatsii konstitutsionnogo prava na dostovernuyu informatsiyu o sostoyanii okruzhayushchei sredy // Alleya nauki. 2019. T. 2. № 1 (28). S. 755-759.

2. Mel'nikova V.G. Otkrytie dannye v mekhanizme realizatsii prava grazhdan na dostovernuyu informatsiyu o sostoyanii okruzhayushchei sredy // Vestnik Tomskogo gosudarstvennogo universiteta. Ser.: Pravo. 2017. № 23. S. 124-130.

3. Guseinova R.A. Pravo grazhdan na informatsiyu o sostoyanii okruzhayushchei sredy // Aktual'nye voprosy sovremennoi ekonomiki. 2019. № 4. S. 1358-1367.

4. Brinchuk M.M. Ekologicheskoe pravo: uchebnik. M., 2011. $624 \mathrm{~s}$.

5. Zhilin S.M. Ekologiya. Informatsiya. Obshchestvo: monografiya. Kaliningrad, 2000. 310 s.

6. Ekologicheskoe pravo: uchebnik / pod red. O.I. Krassova. 4-e izd., peresmotr. M.: Yur. norma, NITs INFRA-M, 2019. $528 \mathrm{~s}$.

7. VTsIOM. Indeks informirovannosti o soderzhanii Konstitutsii za 2018 god. [Elektronnyi resurs]. URL: https://wciom.ru (data obrashcheniya: 25.12.2019). 
8. Deklaratsiya Konferentsii Organizatsii Ob"edinennykh Natsii po problemam okruzhayushchei cheloveka sredy 1972 goda // Mezhdunarodnoe ekologicheskoe zakonodatel'stvo: sb.st. Kiev, 2019. 414 s.

9. Rio-de-Zhaneirskaya deklaratsiya Organizatsii Ob"edinennykh Natsii po okruzhayushchei srede i razvitiyu 1992 goda // Mezhdunarodnoe ekologicheskoe zakonodatel'stvo: sb. st. Kiev, 2019. 414 s.

10. O dostupe $\mathrm{k}$ informatsii, uchastii obshchestvennosti $\mathrm{v}$ protsesse prinyatiya reshenii $\mathrm{i}$ dostupe $\mathrm{k}$ pravosudiyu po voprosam, kasayushchimsya okruzhayushchei sredy: konventsiya Evropeiskoi Ekonomicheskoi Komissii Organizatsii Ob"edinennykh Natsii ot 25 iyunya 1998 g. // Mezhdunarodnoe ekologicheskoe zakonodatel'stvo: sb. st. Kiev, 2019. 414 s.

11. Konstitutsiya Respubliki Belarus' ot 15 marta 1994 g. Minsk, 2019. 37 s.

12. Ob ekologicheskoi informatsii: zakon FRG ot 8 iyulya 1994 g. // Zarubezhnoe ekologicheskoe zakonodatel'stvo: sb. Kaliningrad, 1996. 309 s.

13. Zakon o svobode informatsii 1966 goda SShA // Zarubezhnoe ekologicheskoe zakonodatel'stvo: sb. Kaliningrad, 1996. $309 \mathrm{~s}$.

14. The Environmental Performance Index 2018 god. [Elektronnyi resurs]. URL: https://epi.envirocenter.yale.edu/downloads/epi2018policymakerssummaryv01.pdf (data obrashcheniya: 25.12.2019).

15. Vsemirnaya organizatsiya zdravookhraneniya: ofitsial'nyi sait. [Elektronnyi resurs]. URL: https://www.who.int/ru (data obrashcheniya: 25.12.2019).

16. Kodeks Rossiiskoi Federatsii ob administrativnykh pravonarusheniyakh ot 30 dek. 2001 g. № 195-FZ. M., 2019. $63 \mathrm{~s}$.

17. Ob okhrane okruzhayushchei sredy: feder. zakon Ros. Federatsii ot 10 yanv. 2002 g. № 7-FZ: s izm. i dop. Dostup iz sprav.-pravovoi sistemy «Konsul'tantPlyus». 